\title{
Discussion on New Ideas of Architectural Art Teaching in Multimedia Era Under the Framework of Aesthetic Education
}

\author{
Yan Huang \\ Xiamen University Tan Kah Kee College \\ Zhangzhou, China
}

\begin{abstract}
Under the framework of aesthetic education, teachers are unequivocally committed to the aesthetic literacy improvement project of architectural students. In addition to cultivating students' artistic foundation and improving their performance ability, it is more important to make full use of and extensively combine multimedia resources and effectively enhance students' aesthetic quality through various means, making it a strong support for architectural design. To achieve ideal results, the author thinks that efforts should be made from the following aspects: first, seeking new ideas from the teaching of basic colors; second, emphasizing the important position of architectural sketching in the basic curriculum; third, advocating instructive teaching instead of formulated teaching; fourth, creating a variety of extracurricular learning aids; fifth, experimenting with the classified teaching mode. The architectural arts education should be put to more importance; for only those architects cultivated have excellent aesthetic accomplishment can make great achievement in architecture. How to establish an architectural aesthetic education system that adapted to the development of the times in multimedia era is the issue that we should face, discuss and move towards together.
\end{abstract}

Keywords-aesthetic education; architectural art teaching; artistic accomplishment

\section{INTRODUCTION}

In a letter of reply to an aged professor in Central Academy of Fine Arts on August 30, 2018, President Xi Jinping pointed out: "As an important part of aesthetic education, art education has a significant effect in shaping beautiful mind. And it's necessary for you to strengthen efforts in aesthetic education." ${ }^{1}$ At the national conference on school aesthetic education held on April 21, 2018, minister of education Chen Baosheng stressed: "' we should firmly push forward innovative development of school aesthetic education in the new era guided by Xi Jinping Thoughts on Socialism with Chinese Characteristics for the new era. A famous Chinese educationist Cai Yuanpei, at a speech in "Shenzhou Society" in early 20 century, proposed the education concept of "replacing religion with aesthetic education", ${ }^{2}$ advocating establishing an aesthetical ideology

China Education Daily, 1st edition, April 23, 2018.

La Jeunesse, Vol. 3, No. 6 (published on August 1, 1917). that goes for the heart forming a really beautiful world with art.

Therefore the importance of aesthetic education can be seen. In the aspect of architectural art in colleges and universities, teachers are duty-bound to improve students' aesthetic literacy. In addition to cultivating students' art foundation and improving their artistic expression, it is more important to effectively improve students' aesthetic literacy through basic teaching, and make it a strong support for architectural design.

\section{NEW IDEAS OF BASIC COLOR TEACHING}

In the multimedia era, computer technology has been widely used in every subject, and architecture is no exception. However, students are faced with the problem of color recognition and sensitivity while using computer software to select colors. Such a new situation requires that the color teaching of architectural art should, in limited time, not only teach students relevant color knowledge and train students' basic expression skills, but also guide them to establish their own color aesthetic system. Therefore, the color course reform in the current architectural art teaching is worth discussing.

The traditional teaching mode of architectural colors pays attention to technique, in which how to draw and how to draw lifelike are the key requirements of teaching. However, in the face of the current wide involvement of multimedia in the field of design under the new situation, as well as the phenomenon that student of science and engineering have weak color sense and insufficient architectural art class, it is obviously a cultivating mode with relatively slow effect and is not suitable for the current training mode any more.

The color teaching, as the support of architectural design course, needs to meet three basic requirements to achieve full results:

- making students master color rules and use them freely;

- making the student have certain performance ability in color work;

- improving students' systematic Chromatics literacy. 
Sketching is the traditional means of color course teaching and also an extremely necessary teaching content. Through sketching students can be trained in observation and performance, and at the same time improve color recognition and aesthetic taste. Since most of the students in architecture major are science and engineering background that lack of systematic theoretical knowledge of color and freehand painting performance, it's advisable to try to start from the color and graphic composition. First use the color harmony exercise as the entry point and simply analyze the color without requirements in technical level, which will be more conducive to learning and absorption. First to make the connection from sketch to the color relations, the black and white color gradient exercise should be conducted at the beginning; then it should be the transition to analyze the gradual relation of colors in the same color system, such as: harmony and contrast training of similar colors and analogous colors; then the harmony exercise on the original color, intermediate color, compound color should be carried out. After that that it will be relatively smooth to get to the integrated color plane composition training when the students have certain knowledge of color harmony and color relationship, they can be better at selecting and matching colors in computer software and apply this ability to designing. Of course, the training of spatial color relations and expression techniques is also crucial to the improvement of students majoring in architecture. Therefore it is better to start from the stationary sketch, then get to the sketch of indoor scenes and finally transit to the sketch of landscapes outside Watercolor or gouache, are most commonly used two types in the color teaching of architectural art. Each has advantages in the picture effect, but their learning process is different. Therefore, try to choose one to the end, and avoid two kinds of painting being introduced in the same course at the same time, which will cause confusion to students.

\section{NON-NEGLIGIBLE ROLE OF ARCHITECTURAL SKETCH IN ART COURSE}

As the development of technology in recent years, computer-based drafting has been widely used in design, while its efficiency and rapidness make the hand drawing ability of designers atrophy increasingly. In this context, the concept of "sketch is no longer important" is increasingly influencing the teaching process of architectural art in colleges and universities. However, when we look at the architectural design masters at home and abroad, we find that they all have extraordinary sketching and artistic creativity. So it can be seen that architectural sketch is still an important way of modeling art training and the foundation of architectural design. The level of architect sketch has a direct impact on the level of its design. That's because the architect needs to collect design materials, obtain design inspiration, promote the formation and perfection of the concept sketch and finally facilitate the presentation of the design plan, through architectural sketches. Therefore, sketch plays an irreplaceable role in architecture.

Above all sufficient total class hours and class hours per week should be guaranteed so that zero-based students can have enough time to master sketching skills; secondly in the course setting, imitation can be set as a starting point, making students learn the master works from partially to completely and absorbing nutrients from those works; and then teachers can choose pictures similar to the copying pictures for students' reference when sketching so students can make significant progress; at last, outdoor realistic painting for more than 3 weeks should be arranged if possible. In addition to the application of the basic laws of aesthetics in the picture, outdoor sketching is also affected by the synthetical factors such as weather, time and environment. This contributes to the training of students' comprehensive ability the improvement of and their ability to observe, analyze and express architecture and its surrounding environment; furthermore, the arrangement of the content of courses should be combined with designing factors, that is, to focus on cultivating students to shift from expressing thinking to designing thinking through relative subtractions and supplements, abstraction and exaggeration, and association and creativity training. In this way students can improve their modeling, expressing, and observing as well as creativity ability through the learning of architecture sketching and lay a solid foundation for future development.

\section{THE AdVOCATION OF THE REPLACEMENT OF FoRMULATIVE TEACHING WITH INSTRUCTIVE TEACHING}

At present, many students majoring in architecture in universities have weak art foundation and a considerable number of students even have a fear of art classes. Neither do they understand the purpose of the art curriculum nor do they have much interest in learning it. Faced with such reality, architectural art teachers have gradually formed two main teaching concepts in their long-term teaching practice. The first is that the most convenient way to reflect the teaching effect in a short time is a pattern similar to intensive training. This pattern is to develop a series of stylized templates, for demonstration in each class, to let students learn by rote and apply mechanically in drawing. Such teaching method does bring fast effect but it has a color of utilitarianism with seeming achievements. But actually students just swallow the templates and can't have their aesthetic judgment improved, not to mention creativity. Under such teaching mode students are often not able to sketch while they can copy; or they don't know how to express the right effect in a different time or place or in another form; even some students who can make excellent picture effect can only use the same technique to express scenes in different environments, lights and situations and thus have their development of design thinking hampered. As can be seen, such stylized teaching cannot fundamentally improve students' aesthetic ability.

It is true that the application of stylized teaching in the primary stage is helpful to students' learning in terms of standardization and inheritance for it enables students to accumulate and draw lessons in the basic learning stage and enhances their self-confidence on the sight of rapid achievements. However when the existing norms weaken students' own subjective feelings to a secondary position, the unique and most essential desire of expression of students will be damaged thus they will fall into the prison of piling 
up formulas. In view of this, a teaching method that is more conducive to students' long-term development. Therefore, another teaching concept - instructive teaching is admired by more architectural art teacher. The ultimate way is to arouse students' enthusiasm and initiative and guide them to think independently, explore actively to consciously grasp art knowledge, improve the ability to analyze images and solve problems, improve aesthetic taste and develop creativity. Only such students cultivated can have stronger competitiveness in the society. Therefore instructive teaching method is worth emphasis for the time being. The following basic requirements can be implemented in art teaching:

- It should be recognized that students are the subject of teaching activities. Teachers should not give too much of their own personal opinions, let alone force all students to learn a single form of expression. Students should be left more time after class to practice and develop their learning enthusiasm and initiative to find methods and answers through various forms of homework. Public evaluation of paintings and drawings from time to time can be organized in any class, in which the mutual evaluation among students will replace the "teacher talk only" to promote the mutual learning and common growth of students.

- Students should be allowed to question and guided to learn to think. They are supposed to be taught in different ways according to their different characteristics and encouraged to express the images in their way boldly.

- Students should be inspired to treat problems with connective viewpoint, observing, thinking, and mirroring things more to draw inferences so that their relative thinking can be developed.

\section{THE ESTABLISHMENT OF DIVERSIFIED EXTRACURRICULAR AIDS TO LEARNING}

Architectural art teaching must keep pace with the times, develop ideas, break stereotypes, make full use of and extensively integrate multi-media resources, carry out extracurricular auxiliary teaching, and make it a powerful supplement and extension of classroom teaching. Compared with classroom teaching, there are many multimedia extracurricular AIDS, such as Rain Classroom, Intelligent class, Flipped Classroom, Mooc and Micro-class. Compared with traditional classroom teaching, multimedia is more flexible and diversified, which can provide greater assistance to classroom teaching to a certain extent. Students should be encouraged to embrace such classrooms actively.. In addition, there are other forms of extra-curricular learning AIDS. For example: the teaching unit can regularly organizes the student to visit art galleries, museums, artist studios and all kinds of art and design exhibition, arrange specialists to give seminars in colleges, strengthen academic exchanges between colleges and universities at home and abroad, hold exchange exhibitions, achievements show, Sketching Works Exhibition, etc., to create a diverse art learning conditions for students and assist students' systematic learning of architectural art. At the same time, students are encouraged to take an active part in various art competitions and improve their comprehensive artistic accomplishment, so as to promote the more active, serious and conscious engagement of students in learning. By means of multiple extracurricular assistive learning, students can broaden their art vision and enhance their art cognition and artistic accomplishment

\section{The AtTempt of Classified Teaching Mode}

In general, there is obvious distinction of level after a semester of students' admission. Therefore from the second semester, classified teaching mode according to students' grades in the first semester can be implemented. Teaching students according to their aptitude and restricting egalitarianism will promote students' active learning ability. The teaching unit can try to classify students into three categories and give them different requirements accordingly: First, students with solid art foundation should be assigned to more training of sketching and creating with increased difficulty. The extension and expansion of learning should be emphasized to guide students to express their creativity and ideas with feelings. Second, students with moderate art foundation can be taught in the mode combining imitating with sketching and be encouraged to observe more, practice more, read picture albums more, to enhance expression ability, promote aesthetic taste and develop creativity. Third, students with weak art foundation should be taught from the threshold knowledge and move to the next topic only after students digest all the basic subjects. students of each category should be encouraged be help each other, that means students with good foundation can guide those with weak foundation and compete with each other, thus forming a positive competitive activation mechanism to drive the common growth of the whole group.

In classified teaching, students can learn from each other, supervise and catch up with each other, which are both a challenge and a promotion to the teaching mode and structure of the original average treatment. It can not only enhance students' consciousness of independent studying, but also contribute to the improvement of the teaching level and ability of art teachers.

\section{CONCLUSION}

The architectural arts education should be put to more importance; for only those architects cultivated have excellent aesthetic accomplishment can make great achievement in architecture. How to establish an architectural aesthetic education system that adapted to the development of the times in multimedia era is the issue that we should face, discuss and move towards together.

\section{REFERENCES}

[1] Han Yuhong, Han Chengyuan. Art foundation - color. Beijing: China Architecture \& Building Press; 1st edition. January 2006(in Chinese)

[2] Li Ang. On the cultivation of creative thinking ability in architectural art teaching. Journal of Henan Institute of Education (Philosophy and Social Sciences Edition). 1999(4): 93-95. (in Chinese) 
[3] Zhang Yanjun. On the importance of design sketching in teaching. Art Panorama. 2010:01. (in Chinese)

[4] Yu Xiang. Architectural sketch. Beijing: China Machine Press; 2nd edition. August 2010. (in Chinese)

[5] Zhou Hongzhi. Architectural art — watercolor. Beijing: China Electric Power Press; 2nd Edition. June 2012. (in Chinese)

[6] Luo Kezhong. Design and hand-painted series - pen light color architectural landscape techniques. Liaoning: Liaoning Fine Arts Publishing House; May 2014(in Chinese)

[7] Zeng Fanren. On the significance of modern aesthetic education. Journal of Shandong University (Philosophy Edition). 1997: 25-27. (in Chinese)

[8] An Ning. Color principle and color composition. Hangzhou: China Academy of Art Press; 1st edition. May 1999. (in Chinese) 